\title{
TORNADO-LEVEL ESTIMATES OF SOCIOECONOMIC AND DEMOGRAPHIC VARIABLES
}

\author{
Tyler Fricker ${ }^{1}$
}

\begin{abstract}
Tornadoes create a threat to human life. Knowing the conditions that make people vulnerable to this threat is vitally important. Yet, socioeconomic and demographic data are not consistently available at the tornado level making it hard to obtain this knowledge. In response to this limitation, here a method to estimate socioeconomic and demographic variables in a consistent manner at the tornado level for historical events is implemented and assessed. The daysmetric method uses data from the 1990 and 2000 Census, as well as the 2010 American Community Survey together with tornado reports over the period 1995-2016. Results show that a typical casualty-producing tornado affects 34 people with an interquartile range between 4 and 198 people. Results also show that the 2 July 1997 Detroit, Michigan tornado with its 90 known injuries likely affected nearly 101,752 people. Comparisons between estimates using the actual path and a simplified modeled path show strong correspondence (percent errors averaging less than 10\%) and estimates compare favorably (correlations exceeding .90) with known demographic numbers from a sample of tornadoes indicating the procedure provides useful information for statistical studies of tornado vulnerability.
\end{abstract}

Keywords: Tornado, Casualties, Demographics

\section{INTRODUCTION}

The United States experiences more tornadoes - rapidly rotating columns of air - than anywhere else on Earth (Grazulis 1990). Tornadoes affecting urban areas have the potential

\footnotetext{
${ }^{1}$ Department of Geography, Florida State University, 113 Collegiate Loop, Tallahassee, FL, 32306 Email: tfricker@fsu.edu
} 
to cause hundreds or thousands of casualties - injuries and deaths. Data from the Storm Prediction Center of the National Oceanic and Atmospheric Administration show that the 27 April 2011 Tuscaloosa-Birmingham, Alabama tornado resulted in 1,564 casualties including 64 deaths. Less than a month later the 22 May 2011 Joplin, Missouri tornado resulted in 1,308 casualties including 158 deaths. In 2011 alone tornadoes were responsible for 553 deaths in the United States (National Centers for Environmental Information 2012). More recently, the 26 December 2015 Garland-Rowlett, Texas tornado resulted in 478 casualties including ten deaths.

Fast winds, short warning times, and quality of built environments are the leading proximal causes of casualties (Greenough et al. 2001). In addition, research shows that beyond tornado strength and the number of people in harm's way (Fricker et al. 2017a), per-tornado casualty counts depend on housing stock (permanent or mobile), and age and income of the occupants (Bohonos and Hogan 1999; Greenough et al. 2001; Simmons and Sutter 2005; Simmons and Sutter 2008; Simmons and Sutter 2009). Other socioeconomic and demographic determinants include poverty and education (Simmons and Sutter 2014; Lim et al. 2017) but the significance and relative importance of these other factors remains in question, partly due to the application of different estimation approaches.

Using county-level socioeconomic and demographic data and a straight line as a model for the tornado 'footprint' Simmons and Sutter $(2005,2008,2009)$ evaluate risk factors for casualties and find a positive correlation with income and percentage of mobile homes after controlling for the damage rating. Lim et al. (2017) find similar correlations but note a positive relationship between deaths and percentage of households headed by women when other variables like income, poverty rate, educational attainment, and mobile homes are omitted. Simmons and Sutter (2014) use the same approach to predict per-tornado fatalities during 2011. Fricker et al. (2017a) use a more detailed model for the tornado footprint and produce tornado-level estimates of energy dissipation and population with a dasymetric approach on grid-level data. Masoomi and van de Lindt (2018) use a similar footprint model 
to produce tornado-level estimates of population and housing units from Census block-level data. With the considerably more granular data they improve on the predictive skill of Simmons and Sutter (2014) - on same set of violent tornadoes in 2011-using maximum damage rating, path length, and number of people in the tornado path as fixed effects.

The above studies demonstrate the potential of statistical models for understanding tornado vulnerability. However, a drawback to realizing this potential is the inconsistency in the data, which can lead to contradictory results even when the model is the same, as well as the different tornado models and levels of aggregation used by researchers. In response, the main purpose of the present work is to provide a consistent set of socioeconomic and demographic numbers at the tornado-level in order to benchmark the performance of models used in analyzing and predicting tornado casualties. The approach to obtain these numbers is to use a suitable level of aggregated socioeconomic and demographic data and to include potential relevant variables like race, age, and income. The result is a data set of per-tornado estimates that will be used to analyze and predict casualties with greater accuracy and consistency. Importantly, the numerical estimates highlighted in this paper can be reproduced exactly using the available code developed from the $\mathrm{R}$ project for statistical computing ( $\mathrm{R}$ Core Team 2016).

\section{DATA}

\section{Historical Tornado Reports}

Official tornado reports are obtained from the U.S. Storm Prediction Center (SPC). The SPC database has information related to the spatial location and dimensions of the damage path. The database is compiled from National Weather Service (NWS) Storm Data and includes all known tornadoes dating back to 1950. Specifically, each tornado record includes information on initiation point (latitude and longitude), date, length and width of the damage path, and maximum damage rating from 0 to 5 (in Fujita (F) (prior to February 2007) or Enhanced Fujita (EF) (thereafter) damage scale). It also includes the number of deaths and injuries. Tornado reports in the database are compiled initially by the NWS 
offices and reviewed by the National Centers for Environmental Information (formerly the National Climate Data Center) (Verbout et al. 2006) before entering the database. The database is available in a shapefile format with each tornado represented geometrically as a straight-line track between the start (initiation point) and end locations. Here all tornadoes in the database from the historical period 1995-2016 are considered. The start year coincides with the period of record where maximum path width was adopted by the NWS. The end year is the last available to the authors at the time of analysis.

Tornado reports include information on the number of deaths and injuries. When available, they also include information on the age and sex of each fatality. For example, the Storm Events database lists the fatality details from the 22 May 2011 Joplin, Missouri tornado showing the age and sex of each death. But these event-fatality details are not available for every tornado. Details from the 29 May 1995 Great Barrington, Massachusetts tornado that produced 27 casualties with three deaths, for example, includes no information on either the age or the sex of the victims. Moreover, missing from all tornado reports is information on the race or socioeconomic status of the victims. For example, although it is known that $54 \%$ of the deaths from the 2011 Joplin, Missouri tornado were women, no information on race or income of these casualties exists.

\section{Census Tract Socioeconomic \& Demographic Data}

Socioeconomic and demographic data are obtained from the United States Census Bureau and the American Community Survey (ACS). The associated boundary shapefiles are obtained from the topologically integrated geographic encoding and referencing (TIGER) database. The ACS is a nationwide survey that collects and produces information on demographic, social, economic, and housing characteristics every year. The survey includes information at the state, county, tract, block group, and block level. Here Census tract data are used so as to be large enough to include estimates of most socioeconomic and demographic variables and small enough to give more detailed estimates than other geographies. This study includes the 1990 and 2000 Census, as well as the 2010 ACS five-year estimates. 
The 2010 Census is not considered because it is a short-form only Census that asks for information on just name, sex, age, date of birth, race, ethnicity, relationship, and housing tenure.

Differences in the quality of data exist between the decennial census-here 1990 and 2000 - and the ACS. Though the long form remained largely consistent between the 2000 decennial census and the ACS, the data collection strategy changed quite drastically. For example, the 2000 Census sampled approximately 19 million households to collect long-form data, while the ACS contacts a sample of households each month, amounting to approximately 3.54 million households each year (Folch et al. 2016). As a result of this reduction in sample size, the margins of error associated with ACS estimates at most geographies increased, making it important to recognize the challenges of using ACS estimates, in part, to their potentially high levels of uncertainty (Macdonald 2006; Salvo and Lobo 2006; Bazuin and Fraser 2013; Spielman et al. 2014; Folch et al. 2016).

\section{TORNADO MODEL AND DASYMETRIC METHOD}

A model for each tornado path is made using a buffer on the straight line track in accordance with the recorded path width. Over the conterminous United States during the period 1995-2016 there were 26,863 tornadoes. Of these, 2,208 were casualty-producing and of these 2,201 were casualty-producing tornadoes that occurred over a geography with socioeconomic and demographic data available (Fig. 1). Estimates of social correlates within the path are computed for each tornado. This is done using a dasymetric procedure similar to that used in Fricker et al. (2017b). The procedure requires two sets of volumetric areal data. The first set is the spatial path of the tornado. The second set is socioeconomic and demographic data and its areal representation as Census tracts.

The dasymetric calculations are similar to those made in Fricker et al. (2017b) but differ in perspective. Fricker et al. (2017b) use tornado-level information (e.g. the number of injuries) to estimate where (e.g. what jurisdiction) those injuries are most likely to have occurred. Here jurisdiction-level information (e.g. Census tracts) is used to estimate how 
many people by socioeconomic or demographic group were in the path of the tornado. More specifically, the central premise is that a reliable estimate of tornado-level socioeconomic and demographic data can be made with spatial apportionment of the Census information. Using a ratio of the fraction of the tornado path that occurs within a Census tract and the total area of the Census tract, weighted estimates of variables (e.g. household median income) can be made for each fraction of the tornado path. When added together, the result is an estimate of the variable (e.g. household median income) for the entire tornado path (Fig. 2). Final values are determined using linear interpolation based on the year of occurrence. Tornadoes on or after 2010 are assigned estimates based on the year 2010 .

With the goal to better understand tornado casualties, socioeconomic and demographic variables that can influence the rate of tornado casualties are further examined. Variables chosen are based on previous research (Simmons and Sutter 2005; Simmons and Sutter 2008; Simmons and Sutter 2009; Simmons and Sutter 2011; Ashley 2007; Paul and Stimers 2012; Paul et al. 2014; Lim et al. 2017; Masoomi and van de Lindt 2018) and include total population, population density, male population, female population, white population, black population, household median income, and number of mobile homes. Of additional interest is population by age groups (under 18, 18-44, 45-64, and over 65). Population data (total population, male population, female population, white population, black population, and population by age) are in number of people. Population density are in people per square kilometer. Household median income data are in 2015 dollars, converted using the Consumer Price Index (CPI-U) and mobile home data are in number of mobile homes.

As previously mentioned, it is important to recognize the challenges in using ACS estimates. Here, the challenge of creating reliable estimates is rooted in the margins of error (MOE) attached to the 2010 ACS five-year estimates (Table 1). For the seven variables of interest with direct MOE (total population, number of males, number of females, white population, black population, household median income, and number of mobile homes), the lowest associated MOE for all tracts is found in population counts (excluding black popu- 
lation) and household median income. Conversely, the largest associated MOE is found in the number of mobile homes, which is likely the result of a small number problem. In fact, $35 \%$ of all tracts in the 2010 ACS five-year estimates have less than 50 mobile homes. For the five variables of interest with no direct MOE (population density, and population by age groups), a new MOE was calculated using the Census Bureau's directions for derived estimates (United States Census Bureau 2008). The associated MOE range from an average low of $2 \%$ (people 18-44) to an average high of $9 \%$ (population density), with a median low of $2 \%$ (people 18-44) to a median high of $8 \%$ (population density), and an interquartile range between $2 \%$ and $11 \%$.

\section{RESULTS}

\section{Socioeconomic/Demographic Estimates Per Tornado}

The procedure results in estimates of twelve variables that can be analyzed independently or in combination with other attributes in the SPC database. For the set of 2,201 tornadoes, the median total population is 33.7 people with an interquartile range between 3.71 and 198 people. The median population density is 20.1 people per square kilometer with an interquartile range between 7.83 and 65.6 people per square kilometer. The method estimates that as many as 101,752 people - given tract-level information of residential population and not actual population numbers - were in the path of the 2 July 1997 Detroit, Michigan tornado that resulted in 90 injuries. Of the top ten tornadoes ranked by total population (Table 2), only one (1997 Detroit, Michigan tornado) is estimated to have impacted over 100,000 people. The next closest tornado (the 2013 St. Louis, Missouri tornado) is estimated to have impacted 36,840 people - given tract-level information of residential population and not actual population numbers.

For the same set of tornadoes, the median number of males is 16.9 with an interquartile range between 1.9 and 98. Similarly, the median number of females is 16.9 with and interquartile range between 1.9 and 100. The median white population is 26.8 people with an interquartile range between 2.82 and 155 people, and the median black population is 
.85 people with an interquartile range between .04 and 13.2 people. On average, casualtyproducing tornadoes have impacted nearly three times as many white people (344 people) as black people (130 people).

Additionally, the median household median income is $\$ 46,988$ with an interquartile range between $\$ 39,559$ and $\$ 56,366$ and the median number of mobile homes is 1.68 with an interquartile range between .18 and 9.5. It is estimated that as many as 821 mobile homes were in the path of the 27 April 2011 Hackleburg-Phil Campbell, Alabama tornado that resulted in 145 injuries and 72 deaths. Of the top 10 tornadoes ranked by the number of mobile homes (Table 3), only two (1999 Bridge Creek-Moore, Oklahoma and 2012 Wichita, Kansas tornadoes) occurred in states outside of the Southeast. Five of the top ten tornadoes ranked by the number of mobile homes occurred in the state of Alabama alone.

\section{Comparisons Between Estimates Using Actual and Modeled Paths}

The reliability of the per-tornado estimates of socioeconomic and demographic variables hinges on the assumption that a rectangular - or buffered straight-line - path is a reasonable approximation to the actual path. The start and end locations plus the path width define a rectangle path model but tornadoes never exactly fit this model. Figure 3 shows modeled and actual paths for 20 casualty-producing tornadoes. The actual paths are downloaded from the NWS Damage Assessment Toolkit (DAT), which is a geographic information system (GIS) based framework for collecting, storing, and analyzing damage survey data, using the EF-scale for damage classification (Fricker et al. 2014). The choice of tornadoes for comparisons is a combination of random selection and availability conditional on the most extreme events - with the highest number of casualties. As can be seen, for some tornadoes the model provides an excellent overlay to the actual path but not for all. Importantly are the differences in socioeconomic and demographic estimates for modeled and actual paths, which can be seen in Table 4.

Of the 20 casualty-producing tornadoes with both modeled and actual paths, the largest over-estimation for total population is the 2011 Tuscaloosa-Birmingham, Alabama tornado. 
The procedure estimates that as many as 25,793 $( \pm 2,373)$ people were within the tornado's path given a modeled path, which is 6,878 more people than the estimated $18,915( \pm 1,740)$ people within the tornado's path given the actual path. The largest under-estimation for total population is the 2011 Joplin, Missouri tornado. The procedure estimates that as many as 2,688 $( \pm 242)$ people were within the tornado's path given a modeled path, which is 11,374 fewer than the estimated $14,062( \pm 1,294)$ people within the tornado's path given the actual path. These large over- and under-estimates, however, appear to be outliers, as the remaining 18 tornadoes with both modeled and actual paths do not differ by more than 700 people.

Further, modeled path estimates of socioeconomic and demographic values are compared to actual path estimates of socioeconomic and demographic variables for the set of 20 casualty-producing tornadoes. The Pearson correlation between modeled and actual path estimates is above .67 for all variables and above .83 when the white population variable is removed (Table 5). The root-mean-square-error (RMSE) between modeled and actual path estimates for total population is 775 people and the RMSE for population density, number of males, number of females, white population, and black population is 57 people per square kilometer, 277 people, 498 people, 650 people, and 68 people, respectively. The RMSE between modeled and actual path estimates for household median income is $\$ 575$ and the RMSE for the number of mobile homes is 44 .

The percent error is the RMSE divided by the actual path estimates. The average percent error for all but one (black population) of the variables is below 10\% (Table 5). The high percent error of the estimated black population is attributed to the low numbers of black people affected by the 20 tornadoes chosen. When a subset of the 20 tornadoes consisting of only tornadoes with an estimated black population of at least 100 is considered, the percent error diminishes to .05\%. As such, the combination of very high correlation between modeled and actual path estimates and low percent errors indicates the methodology is quite useful.

To account for potential sampling errors associated with the ACS, coefficients of vari- 
ation are calculated for each Census tract intersected by actual tornado paths (Table 6). A coefficient of variation (CV) measures the relative amount of sampling error that is associated with a sample estimate. A small CV indicates that the standard error is small relative to the estimate, while a large $\mathrm{CV}$ indicates that the standard error is large relative to the estimate. Small CVs are more reliable than large CVs. For the set of seven variables of interest with direct MOE (total population, number of males, number of females, white population, black population, household median income, and number of mobile homes), the lowest associated CV for tracts is found in population and household median income, while the largest associated CV is found in black population and the number of mobile homes.

There are a few different thresholds for reliability when comparing and evaluating ACS data. High and medium reliability exists at a CV below 30\%, while low reliability exists at a CV above 30\%. Of the 141 Census tracts impacted by an actual path, 54 (38\%) have a CV above 30\% for black population, while 42 (30\%) have a CV above 30\% for the number of mobile homes. When only Census tracts with associated CVs above $30 \%$ are used, the average CV drops to $27 \%$ in black population and $22 \%$ in the number of mobile homes - both of which are reliable uncertainty measurements.

To evaluate whether or not differences in estimates can be found by comparing modeled and actual paths, only those tornadoes impacting tracts with CVs below 30\% are considered. Of the initial 20 tornadoes, only 5 impacted at least one Census tract with a CV above $30 \%$ for any variable. For the remaining 15 tornadoes, RMSE and percent error between the modeled and actual path estimates decrease from previous calculations. Thus, the combination of very high correlation between modeled and actual path estimates and low percent errors continues to exist when only those tornadoes overlaying reliable data are used, again indicating the methodology is quite useful.

\section{Correlations Between Actual and Estimated Deaths By Groups}

The approach to obtain reliable estimates is validated by comparing results with demographic statistics of fatalities available in the Storm Events database (https://www.ncdc. 
noaa.gov/stormevents/). The database records all tornado segments from 1950 through 2016. The tornado segments are divided by county and each segment includes both an episode narrative and event narrative. Event fatality data are available within each event and include the type of death - direct or indirect - along with the age, sex, and location - if known - of the victim. No information about injuries is available.

To link the tornado in the SPC database with the associated tornado segments in the Storm Events database, information available in both data sources - both state of occurrence and number of deaths - is used. For example, the 2011 Joplin, Missouri tornado caused 158 direct deaths. To find this tornado in the Storm Events database, search for Missouri in the State/Area drop down menu. Next, choose 22 May 2011 as the begin and end date, and tornado as the event type. After sorting by Death/Injury, the Storm Events database shows an event occurring in Jasper County, Missouri that caused 158 deaths. Choosing the hyper-linked location opens the Storm Events database, where information on the number of deaths, as well as the ages and sex of the fatalities exist.

Estimated deaths by age and sex from the methodology are compared to observed deaths available in the Storm Events database for two dozen tornadoes. Estimated deaths by age and sex are found by multiplying the ratio of the age and sex populations relative to total population with the number of recorded deaths. The tornadoes were chosen as a representative sample to create a wide range of possible fatality estimates. Of these tornadoes, the average number of deaths is 18.3 with a minimum of two and a maximum of 158 . The Pearson correlation between observed and estimated male deaths is .99 $(\mathrm{p}<.001)$ and the correlation between observed and estimated female deaths is .99 ( $\mathrm{p}<.001)$, both indicating a strong relationship (Fig. 4). The Pearson correlation between observed and estimated deaths for people under the age of 18 is $.93(\mathrm{p}<.001)$ and the correlation between observed and estimated deaths for people 18 to 44 , people 45 to 64 , and people over 65 is .97 (p < $.001), .99(\mathrm{p}<.001)$, and $.99(\mathrm{p}<.001)$, respectively, again indicating a strong relationship (Fig. 5). 
The very high correlation between the estimated and observed demographics of fatalities again indicates the methodology is quite useful. Obviously in cases where observed demographics are available they should be used rather than the estimates. However, observed demographics on tornado casualties are limited to deaths and for sex and age groups only. Importantly the methodology provides estimates for any social or demographic variable of interest and appears to do so in a reliable way. Adding additional verification data will likely change the correlation with an anticipated decrease given the large influence of the Joplin tornado. In fact when that verification point is removed, the correlation drops to .72 or above $(\mathrm{p}<.001)$ for age and .95 or above $(\mathrm{p}<.001)$ for sex, both of which remain statistically significant.

\section{UTILITY OF THE ESTIMATES}

Having accurate estimates of socioeconomic and demographic variables at the tornado level allows us to infer aggregate demographics. For instance, using the ratio of the white population relative to total population, the number of white casualties per tornado can be estimated. Similarly, using the ratio of the black population relative to total population, the number of black casualties per tornado can be inferred. The median number of white casualties for the set of 2,201 tornadoes is two $( \pm .26)$ people with an interquartile range of between one $( \pm .13)$ and six $( \pm .78)$. In comparison, the median number of black casualties for the same set of tornadoes is .12 $( \pm .06)$ people with an interquartile range between $.01( \pm$ $.005)$ and $.63( \pm .30)$. The average number of white casualties is nine $( \pm 1.2)$ and the average number of black casualties is slightly less than two $(1.9( \pm .87))$. Of the top ten tornadoes ranked by white casualties (Fig. 6), three occurred in the state of Oklahoma, two in the state of Alabama, and one each in Arkansas, Kentucky, Missouri, Georgia, and Texas. Of the top ten tornadoes ranked by black casualties (Fig. 6), only one (1997 Detroit, Michigan tornado) occurred in a state outside of the Southeast.

Using the ratio of the number of young people (under 18 years old) relative to total population, the number of young casualties per tornado can be estimated. Similarly, using 
the ratio of the number of elderly people (over 65 years old) relative to total population, the number of elderly casualties per tornado can be estimated. The median number of young casualties for the set of 2,201 tornadoes is .64 ( \pm .09$)$ people with an interquartile range between $.28( \pm .04)$ and $1.78( \pm .27)$. In comparison, the median number of elderly casualties is $.37( \pm .03)$ with an interquartile range between $.17( \pm .01)$ and $.99( \pm .08)$. The average number of young casualties is about three $(2.9( \pm .04))$ and the average number of elderly casualties is less than two $(1.6( \pm .13))$. Of the top ten tornadoes ranked by young and elderly casualties (Fig. 7), only one (the 30 May 1998 Spencer, South Dakota tornado) occurred in a state outside the southern Great Plains or Southeast.

Having tornado-level aggregated socioeconomic and demographic information, the next step toward a better understanding of casualties is to examine how these factors relate to death and injury counts. For example, the Pearson correlation between estimated socioeconomic and demographic numbers and the counts of deaths and injuries are seen in Table 7. The coefficients range between -.01 and .43 for deaths and between .01 and .42 for injuries. Moderate correlations are noted between deaths and population, males, females, whites, blacks, and mobile homes. Bi-variate relationships have limited utility in this setting where there are many interacting factors, but they provide clues on what factors might be important. For example, the relatively high correlation with mobile homes is consistent with previous research (Ashley 2007; Simmons and Sutter 2005; Simmons and Sutter 2008; Simmons and Sutter 2009; Sutter and Simmons 2009; Lim et al. 2017), as is the relatively high correlation with race (Donner 2007).

How climate change will influence tornado activity and in turn tornado casualties remains an open and challenging question. Statistically, given a tornado that produces at least one casualty, the casualty rate depends on the number of people in harm's way and on the power of the winds inside the vortex. Using a regression model, Fricker et al. (2017a) find that casualties increase by $33 \%( \pm 3 \%)$ with a doubling of the tornado energy and that casualties increase by $21 \%( \pm 3 \%)$ with a doubling of the number of people affected, on 
average. Including an interaction term in the regression model provides a better description of casualties given population and energy (Elsner et al. 2018a), but these findings are only the beginning as socioeconomic and demographic variables likely impact the casualty rate. Having estimates of these variables at the individual tornado level provides the information needed to build a model that can predict casualty rates from changes in socioeconomic and demographic variables controlling for population and energy.

\section{SUMMARY}

Research shows that beyond tornado strength and the number of people in the path per-tornado casualty counts depend on a number of socioeconomic and demographic factors. The significance and relative importance of these factors remains in question due to inconsistencies in the approaches used to estimate them. In response this paper provides validated estimates of socioeconomic and demographic numbers at the tornado-level. The numbers are validated using known fatalities and actual paths. Strong correlation between estimated and observed fatalities, exceeding .93 for four distinct age groups and .99 for sex, provides a high level of confidence in the estimates.

The socioeconomic and demographic estimates made are influenced by many factors including the assumption of a fixed, straight line representation of the damage path and Census data that are based on the location of residence. Greater spatial precision on the damage path like those available in the NWS DAT would undoubtedly improve the estimates. Moreover, it is reasonable to assume that residential population more closely approximates the number of people in a tornado's path when the tornado strikes at night - and the vast majority of people are at home - than when it strikes during the day. Thus it is likely that time-of-day will be an important variable in any model that explains casualty rates.

Estimates of socioeconomic and demographic variables can provide new insights into the profiles of the populations affected by tornadoes. Additionally, they can be used to create a spatial understanding of certain place vulnerabilities. Furthermore, these estimates can be used to build risk models for tornado casualties that, along with exposure and energy, 
include information about the people that are exposed while controlling for factors like poverty, age, ability, and household status. Importantly, building type, building codes, and how building regulations are unequally implemented and enforced across communities will likely be key model variables. Such models will help articulate why some areas are more vulnerable than others and will help to address questions about tornado casualties related to changing socioeconomic and demographic variables. The models can also be used to project future vulnerability by integrating available Census Bureau's demographic projections. And while the science behind a potential link between tornadoes and climate change is still in its infancy (Elsner et al. 2015; Elsner et al. 2018b), any links that do arise can be incorporated through a modification of the energy term.

Finally, it is envisioned that this approach to augmenting an existing per-event database with casualty demographics can perhaps be used to spark other similar approaches for databases on flood and hurricane casualties. The hope is that this work will spur greater efforts toward keeping track of socioeconomic and demographic information on casualties arising from tornadoes, which may provide insight into vulnerabilities that can drive mitigation strategies and policy changes.

\section{ACKNOWLEDGEMENTS}

The work was partially supported by crowd source funding to the lead author (TF) through experiment.com. The code used to produce the tables and graphs, as well as the data set of tornado-level estimates of socioeconomic and demographic variables is available at https://github.com/tfricker/ Tornado-level-socioeconomic-and-demographic-estimates.

\section{REFERENCES}

Ashley, W. (2007). "Spatial and temporal analysis of tornado fatalities in the United States: 1880-2005." Weather and Forecasting, 22, 1214-1228.

Bazuin, J. T. and Fraser, J. C. (2013). "How the ACS gets it wrong: The story of the 
american community survey and a small, inner city neighborhood." Applied Geography, 45, 292-302.

Bohonos, J. J. and Hogan, D. E. (1999). "The medical impact of tornadoes in north america." The Journal of Emergency Medicine, 17(1), 67-73.

Donner, W. R. (2007). "The political ecology of disaster: An analysis of factors influencing u.s. tornado fatalities and injuries, 1998-2000." Demography, 44(3), 669-685.

Elsner, J. B., Elsner, S. C., and Jagger, T. H. (2015). "The increasing efficiency of tornado days in the United States." Climate Dynamics, 45(3-4), 651-659.

Elsner, J. B., Fricker, T., and Berry, W. D. (2018a). "A model for u.s. tornado casualties involving interaction between damage path estimates of population density and energy dissipation." Journal of Applied Meteorology and Climatology.

Elsner, J. B., Fricker, T., and Schroder, Z. (2018b). "Increasingly powerful tornadoes in the united states." Geophysical Research Letters.

Folch, D. C., Arribas-Bel, D., Koschinsky, J., and Spielman, S. E. (2016). "Spatial variation in the quality of american community survey estimates." Demography, 53(5), 1535-1554.

Fricker, T., Elsner, J. B., Camp, P., and Jagger, T. H. (2014). "Empirical estimates of kinetic energy from some recent U.S. tornadoes." Geophysical Research Letters, 41, 4340-4346.

Fricker, T., Elsner, J. B., and Jagger, T. H. (2017a). "Population and energy elasticity of tornado casualties." Geophysical Research Letters.

Fricker, T., Elsner, J. B., Mesev, V., and Jagger, T. H. (2017b). "A dasymetric method to spatially apportion tornado casualty counts." Geomatics, Natural Hazards and Risk, 8(2), $1768-1782$.

Grazulis, T. P. (1990). Significant Tornadoes, 1880-1989: Discussion and analysis. Significant Tornadoes, 1880-1989. Environmental Films, $<$ http://books.google.com/books?id=E8hFAAAAYAAJ $>$.

Greenough, G., McGeehin, M., Bernard, S. M., Trtanj, J., Riad, J., and Engelbert, D. (2001). "The potential impacts of climate variability and change on health impacts of 
extreme weather events in the United States." Environmental Health Perspectives, 109, $191-198$.

Lim, J., Loveridge, S., Shupp, R., and Skidmore, M. (2017). "Double danger in the double wide: Dimensions of poverty, housing quality and tornado impacts." Regional Science and Urban Economics, 65, 1-15.

Macdonald, H. (2006). "The american community survey: Warmer (more current), but fuzzier (less precise) than the decennial census." Journal of the American Planning Association, 72(4), 491-503.

Masoomi, H. and van de Lindt, J. W. (2018). "Fatality and injury prediction model for tornadoes." Natural Hazards Review, 19(3), 04018009.

National Centers for Environmental Information (2012). "State of the Climate: Tornadoes for Annual 2011.

Paul, B. K. and Stimers, M. (2012). "Exploring probable reasons for record fatalities: the case of 2011 joplin, missouri, tornado." Natural Hazards, 64(2), 1511-1526.

Paul, B. K., Stimers, M., and Caldas, M. (2014). "Predictors of compliance with tornado warnings issued in joplin, missouri, in 2011." Disasters, 39(1), 108-124.

R Core Team (2016). R: A Language and Environment for Statistical Computing. R Foundation for Statistical Computing, Vienna, Austria, <https://www.R-project.org/>.

Salvo, J. J. and Lobo, A. P. (2006). "Moving from a decennial census to a continuous measurement survey: factors affecting nonresponse at the neighborhood level." Population Research and Policy Review, 25(3), 225-241.

Simmons, K. M. and Sutter, D. (2005). "WSR-88d radar, tornado warnings, and tornado casualties." Weather and Forecasting, 20(3), 301-310.

Simmons, K. M. and Sutter, D. (2008). "Tornado warnings, lead times, and tornado casualties: An empirical investigation." Weather and Forecasting, 23(2), 246-258.

Simmons, K. M. and Sutter, D. (2009). "False alarms, tornado warnings, and tornado casualties." Weather, Climate, and Society, 1(1), 38-53. 
Simmons, K. M. and Sutter, D. (2011). Economic and Societal Impacts of Tornadoes. American Meteorological Society, Boston.

Simmons, K. M. and Sutter, D. (2014). "Fatality prediction for the 2011 tornado season based on historical extreme weather data." Natural Hazards Review, 15(3), 04014005.

Spielman, S. E., Folch, D., and Nagle, N. (2014). "Patterns and causes of uncertainty in the american community survey." Applied Geography, 46, 147-157.

Sutter, D. and Simmons, K. M. (2009). "Tornado fatalities and mobile homes in the united states." Natural Hazards, 53(1), 125-137.

United States Census Bureau (2008). "A Compass for Understanding and Using American Community Survey Data: What General Data Users Need to Know.

Verbout, S. M., Brooks, H. E., Leslie, L. M., and Schultz, D. M. (2006). "Evolution of the U.S. tornado database: 1954-2003." Weather and Forecasting, 21, 86-93. 


\section{List of Tables}

1 Summary of the margins of error associated with 2010 ACS five-year estimates. Margins of error are reported as percent error (\%). Margins of error for the number of mobile homes is calculated with tracts containing an estimate of

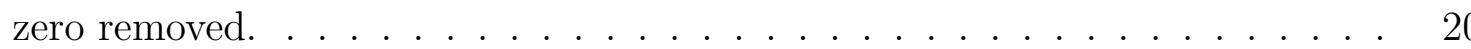

2 Top ten tornadoes ranked by total population in the path. The number of injuries and deaths are given in the SPC tornado database. . . . . . . . . . . 21

3 Top ten tornadoes ranked by the number of mobile homes in the path. The number of injuries and deaths are given in the SPC tornado database. . . . .

4 Differences in demographic numbers estimated from actual and modeled tornado paths. Associated margins of error are shown in parentheses. . . . . . . 23

5 Relationship between modeled path estimates of socioeconomic and demographic variables and actual path estimates of socioeconomic and demographic variables. $r$ is the Pearson correlation between the modeled path estimates and the actual path estimates. RMSE is the root-mean-square-error between the modeled path estimates and the actual path estimates. Percent error is the percent difference between the RMSE and actual path estimates. . . . . 24

6 Summary of the coefficients of variation associated with 2010 ACS five-year estimates. Coefficients of variation are reported as percent error (\%). . . . . 25

7 Relationship between estimated socioeconomic and demographic variables and the number of deaths and the number of injuries. $r_{d}$ is the Pearson correlation between the estimated variable and the number of deaths. $r_{i}$ is the Pearson correlation between the estimated variable and the number of injuries. . . . . 26 
TABLE 1. Summary of the margins of error associated with 2010 ACS five-year estimates. Margins of error are reported as percent error (\%). Margins of error for the number of mobile homes is calculated with tracts containing an estimate of zero removed.

\begin{tabular}{rcccc}
\hline Variable & Mean & $25^{\text {th }}$ Percentile & Median & $75^{\text {th }}$ Percentile \\
\hline Total Population & 9.2 & 6.5 & 8.3 & 10.5 \\
Number of Males & 12 & 8.9 & 11 & 14 \\
Number of Females & 12 & 8.5 & 11 & 13 \\
White Population & 13 & 7.7 & 11 & 15 \\
Black Population & 46 & 28 & 44 & 57 \\
Household Median Income & 15 & 11 & 14 & 18 \\
Number of Mobile Homes & 39 & 24 & 36 & 56 \\
\hline
\end{tabular}


TABLE 2. Top ten tornadoes ranked by total population in the path. The number of injuries and deaths are given in the SPC tornado database.

\begin{tabular}{rccccc}
\hline Location & Date (Year-Month-Day) & Injuries & Deaths & Casualties & Population \\
\hline Detroit, MI & $1997-07-02$ & 90 & 0 & 90 & 101,752 \\
St. Louis, MO & $2013-05-31$ & 8 & 0 & 8 & 36,840 \\
Pittsburgh, PA & $1998-06-02$ & 50 & 0 & 50 & 27,818 \\
Tuscaloosa-Birmingham, AL & $2011-04-27$ & 1,500 & 64 & 1,564 & 25,793 \\
Springfield, MA & $2011-06-01$ & 200 & 3 & 203 & 20,448 \\
Minneapolis, MN & $2011-05-22$ & 48 & 1 & 49 & 19,174 \\
Bridge Creek-Moore, OK & $1999-05-03$ & 583 & 36 & 619 & 19,157 \\
St. Louis, MO & $2011-04-22$ & 5 & 0 & 5 & 18,594 \\
Hackleburg-Phil Campbell, AL & $2011-04-27$ & 145 & 72 & 217 & 17,141 \\
Wichita, KS & $2012-04-14$ & 38 & 0 & 38 & 16,612 \\
\hline
\end{tabular}


TABLE 3. Top ten tornadoes ranked by the number of mobile homes in the path. The number of injuries and deaths are given in the SPC tornado database.

\begin{tabular}{rccccc}
\hline Location & Date (Year-Month-Day) & Injuries & Deaths & Casualties & Mobile Homes \\
\hline Hackleburg-Phil Campbell, AL & $2011-04-27$ & 145 & 72 & 217 & 821 \\
Wichita, KS & $2012-04-14$ & 38 & 0 & 38 & 635 \\
Shoal Creek Valley-Ohatchee, AL & $2011-04-27$ & 85 & 22 & 107 & 616 \\
Vilonia, AR & $2011-04-25$ & 16 & 4 & 20 & 598 \\
Cordova, AL & $2011-04-27$ & 54 & 13 & 67 & 561 \\
Bridge Creek-Moore, OK & $1999-05-03$ & 583 & 36 & 619 & 519 \\
Tuscaloosa-Birmingham, AL & $2011-04-27$ & 1,500 & 64 & 1,564 & 494 \\
Auburn, AL & $2011-11-16$ & 4 & 0 & 4 & 451 \\
Tallulah-Yazoo City-Durant, LA & $2010-04-24$ & 146 & 10 & 156 & 409 \\
Little Rock, AR & $1997-03-01$ & 40 & 10 & 50 & 389 \\
\hline
\end{tabular}


TABLE 4. Differences in demographic numbers estimated from actual and modeled tornado paths. Associated margins of error are shown in parentheses.

\begin{tabular}{|c|c|c|c|c|c|c|c|c|}
\hline \multirow[b]{2}{*}{ Location } & \multicolumn{2}{|c|}{ Total Population } & \multicolumn{2}{|c|}{ Population Density } & \multicolumn{2}{|c|}{ Household Median Income } & \multicolumn{2}{|c|}{ Mobile Homes } \\
\hline & Actual Path & Model Path & Actual Path & Model Path & Actual Path & Model Path & Actual Path & Model Path \\
\hline Tuscaloosa-Birmingham, AL & $18,915( \pm 1,740)$ & $25,793( \pm 2,373)$ & $78( \pm 7)$ & $106( \pm 10)$ & $\$ 48,211( \pm \$ 7,232)$ & $\$ 50,361( \pm \$ 7,554)$ & $343( \pm 134)$ & $494( \pm 192)$ \\
\hline Joplin, MO & $14,062( \pm 1,294)$ & $2,688( \pm 242)$ & $352( \pm 32)$ & $67( \pm 6)$ & $\$ 43,612( \pm \$ 6,542)$ & $\$ 48,647( \pm \$ 7,297)$ & $143( \pm 56)$ & $122( \pm 48)$ \\
\hline Garland-Rowlett, TX & $5,051( \pm 465)$ & $4,837( \pm 445)$ & $609( \pm 55)$ & $584( \pm 53)$ & $\$ 82,456( \pm \$ 12,369)$ & $\$ 82,514( \pm \$ 12,377)$ & $48( \pm 19)$ & $40( \pm 15)$ \\
\hline Arab, AL & $2,014( \pm 185)$ & $2,668( \pm 245)$ & $42( \pm 4)$ & $56( \pm 5)$ & $\$ 44,493( \pm \$ 6,674)$ & $\$ 44,306( \pm \$ 6,646)$ & $128( \pm 50)$ & $158( \pm 61)$ \\
\hline Salem, AL & $1,033( \pm 95)$ & $942( \pm 87)$ & $65( \pm 6)$ & $59( \pm 5)$ & $\$ 52,204( \pm \$ 7,831)$ & $\$ 51,497( \pm \$ 7,724)$ & $125( \pm 49)$ & $136( \pm 53)$ \\
\hline Columbia, MS & $961( \pm 88)$ & $756( \pm 69)$ & $76( \pm 7)$ & $59( \pm 5)$ & $\$ 37,028( \pm \$ 5,554)$ & $\$ 36,964( \pm \$ 5,555)$ & $34( \pm 13)$ & $26( \pm 10)$ \\
\hline Griffin, GA & $844( \pm 78)$ & $1,184( \pm 109)$ & $38( \pm 3)$ & $54( \pm 5)$ & $\$ 51,408( \pm \$ 7,711)$ & $\$ 51,030( \pm \$ 7,654)$ & $78( \pm 31)$ & $101( \pm 40)$ \\
\hline Rochelle, IL & $834( \pm 77)$ & $648( \pm 60)$ & $34( \pm 3)$ & $27( \pm 2)$ & $\$ 67,139( \pm \$ 10,071)$ & $\$ 66,928( \pm \$ 10,039)$ & $24( \pm 9)$ & $19( \pm 8)$ \\
\hline Lutts, TN & $783( \pm 72)$ & $618( \pm 57)$ & $18( \pm 2)$ & $14( \pm 1)$ & $\$ 39,800( \pm \$ 5.970)$ & $\$ 39,585( \pm 5,938)$ & $84( \pm 33)$ & $67( \pm 26)$ \\
\hline Tulsa, OK & $665( \pm 61)$ & $1,037( \pm 95)$ & $65( \pm 6)$ & $101( \pm 9)$ & $\$ 57,431( \pm \$ 8,614)$ & $\$ 53,914( \pm \$ 8,087)$ & $51( \pm 20)$ & $52( \pm 20)$ \\
\hline Cartersville, GA & $591( \pm 54)$ & $765( \pm 70)$ & $25( \pm 2)$ & $33( \pm 3)$ & $\$ 64,495( \pm \$ 9,674)$ & $\$ 63,063( \pm \$ 9,459)$ & $35( \pm 14)$ & $50( \pm 20)$ \\
\hline Brookport, IL & $508( \pm 47)$ & $924( \pm 85)$ & $21( \pm 2)$ & $38( \pm 3)$ & $\$ 50,811( \pm \$ 7,622)$ & $\$ 49,420( \pm \$ 7,413)$ & $47( \pm 18)$ & $67( \pm 26)$ \\
\hline Westville, IL & $385( \pm 35)$ & $301( \pm 28)$ & $38( \pm 4)$ & $30( \pm 3)$ & $\$ 55,898( \pm \$ 8,385)$ & $\$ 56,319( \pm \$ 8448)$ & $27( \pm 11)$ & $22( \pm 9)$ \\
\hline Laurel, MS & $211( \pm 19)$ & $159( \pm 15)$ & $89( \pm 8)$ & $67( \pm 6)$ & $\$ 50,749( \pm \$ 7,613)$ & $\$ 50,850( \pm \$ 7,628)$ & $17( \pm 6)$ & $13( \pm 5)$ \\
\hline Boswell, OK & $154( \pm 14)$ & $208( \pm 19)$ & $3( \pm .3)$ & $4( \pm .4)$ & $\$ 33,729( \pm \$ 5,059)$ & $\$ 33,942( \pm \$ 5,091)$ & $16( \pm 6)$ & $22( \pm 9)$ \\
\hline Katie, OK & $93( \pm 9)$ & $49( \pm 4)$ & $23( \pm 2)$ & $12( \pm 1)$ & $\$ 39,750( \pm \$ 5,963)$ & $\$ 39,582( \pm \$ 5,937)$ & $5( \pm 2)$ & $2( \pm 1)$ \\
\hline Blountstown, FL & $89( \pm 8)$ & $83( \pm 14)$ & $8( \pm 1)$ & $14( \pm 1)$ & $\$ 36,387( \pm \$ 5,458)$ & $\$ 36,236( \pm \$ 5,435)$ & $12( \pm 5)$ & $20( \pm 7)$ \\
\hline Rosalie, AL & $84( \pm 8)$ & $98( \pm 9)$ & $26( \pm 2)$ & $31( \pm 3)$ & $\$ 38,799( \pm \$ 5,820)$ & $\$ 38,827( \pm \$ 5,824)$ & $8( \pm 3)$ & $9( \pm 4)$ \\
\hline Edison, GA & $53( \pm 5)$ & $42( \pm 4)$ & $12( \pm 1)$ & $9( \pm 1)$ & $\$ 27,400( \pm \$ 4,110)$ & $\$ 27,426( \pm \$ 4,114)$ & $6( \pm 3)$ & $5( \pm 2)$ \\
\hline
\end{tabular}


TABLE 5. Relationship between modeled path estimates of socioeconomic and demographic variables and actual path estimates of socioeconomic and demographic variables. $r$ is the Pearson correlation between the modeled path estimates and the actual path estimates. RMSE is the root-mean-square-error between the modeled path estimates and the actual path estimates. Percent error is the percent difference between the RMSE and actual path estimates.

\begin{tabular}{rccc}
\hline Variable & $r$ & RMSE & Percent Error (\%) \\
\hline Total Population & .84 & 775 & 3.7 \\
Population Density & .89 & 57 & 2.8 \\
Number of Males & .85 & 277 & 1.3 \\
Number of Females & .83 & 498 & 4.8 \\
White Population & .67 & 650 & 6.0 \\
Black Population & .99 & 68 & 121 \\
Household Median Income & .99 & 575 & .01 \\
Number of Mobile Homes & .98 & 44 & 2.8 \\
\hline
\end{tabular}


TABLE 6. Summary of the coefficients of variation associated with 2010 ACS five-year estimates. Coefficients of variation are reported as percent error (\%).

\begin{tabular}{|c|c|c|c|c|}
\hline Variable & Mean & $25^{t h}$ Percentile & Median & $75^{\text {th }}$ Percentile \\
\hline Total Population & 6.3 & 4.5 & 5.6 & 7.0 \\
\hline Number of Males & 8.1 & 5.9 & 7.1 & 8.9 \\
\hline Number of Females & 7.8 & 5.7 & 6.9 & 8.5 \\
\hline White Population & 10 & 5.3 & 6.6 & 9.7 \\
\hline Black Population & 40 & 15 & 28 & 55 \\
\hline Household Median Income & 11 & 6.7 & 9.5 & 12 \\
\hline Number of Mobile Homes & 35 & 16 & 22 & 37 \\
\hline
\end{tabular}


TABLE 7. Relationship between estimated socioeconomic and demographic variables and the number of deaths and the number of injuries. $r_{d}$ is the Pearson correlation between the estimated variable and the number of deaths. $r_{i}$ is the Pearson correlation between the estimated variable and the number of injuries.

\begin{tabular}{rcc}
\hline Variable & $r_{d}$ & $r_{i}$ \\
\hline Total Population & .19 & .31 \\
Population Density & -.01 & .01 \\
Number of Males & .20 & .32 \\
Number of Females & .19 & .31 \\
White Population & .32 & .43 \\
Black Population & .05 & .13 \\
Household Median Income & .00 & .04 \\
Number of Mobile Homes & .43 & .42 \\
\hline
\end{tabular}




\section{List of Figures}

1 Casualty producing tornadoes with socioeconomic and demographic data available. Paths of tornadoes with at least one casualty over the period 19952016 are shown as (thin) rectangles. . . . . . . . . . . . . . . . . 28

2 Idealized models of tornado path and household median income. The straightline tornado track (arrow) and damage path (rectangle) are shown over household median income represented by the shaded square cells. The ratio of the fraction of the tornado path that falls within a Census tract (square cells) and the total area of the Census tract are determined by a percent overlay. The weighted estimates of each segment of the tornado path are added to determine an estimate of household median income for the entire tornado path. 29

3 Actual and modeled paths for 20 casualty-producing tornadoes. The actual tornado paths are shown in red and the modeled tornado paths are shown in blue. Boundaries of the Census tracts are shown in gray. . . . . . . . . . . . 30

4 (A) Observed and estimated number of male deaths and (B) observed and estimated number of female deaths. . . . . . . . . . . . . . . . 31

5 (A) Observed and estimated number of deaths age under 18, (B) observed and estimated number of deaths age 18 to 44, (C) observed and estimated number of deaths age 45 to 64, and (D) observed and estimated number of deaths age over $65 . \ldots \ldots \ldots$. . . . . . . . . . . . . . . . . . . . . .

6 Top ten tornadoes by (A) estimated white casualties and by (B) estimated black casualties. . . . . . . . . . . . . . . . . .

$7 \quad$ Top ten tornadoes by (A) estimated young casualties and by (B) estimated elderly casualties. . . . . . . . . . . . . . . . . . 
FIG. 1. Casualty producing tornadoes with socioeconomic and demographic data available. Paths of tornadoes with at least one casualty over the period 1995-2016 are shown as (thin) rectangles.

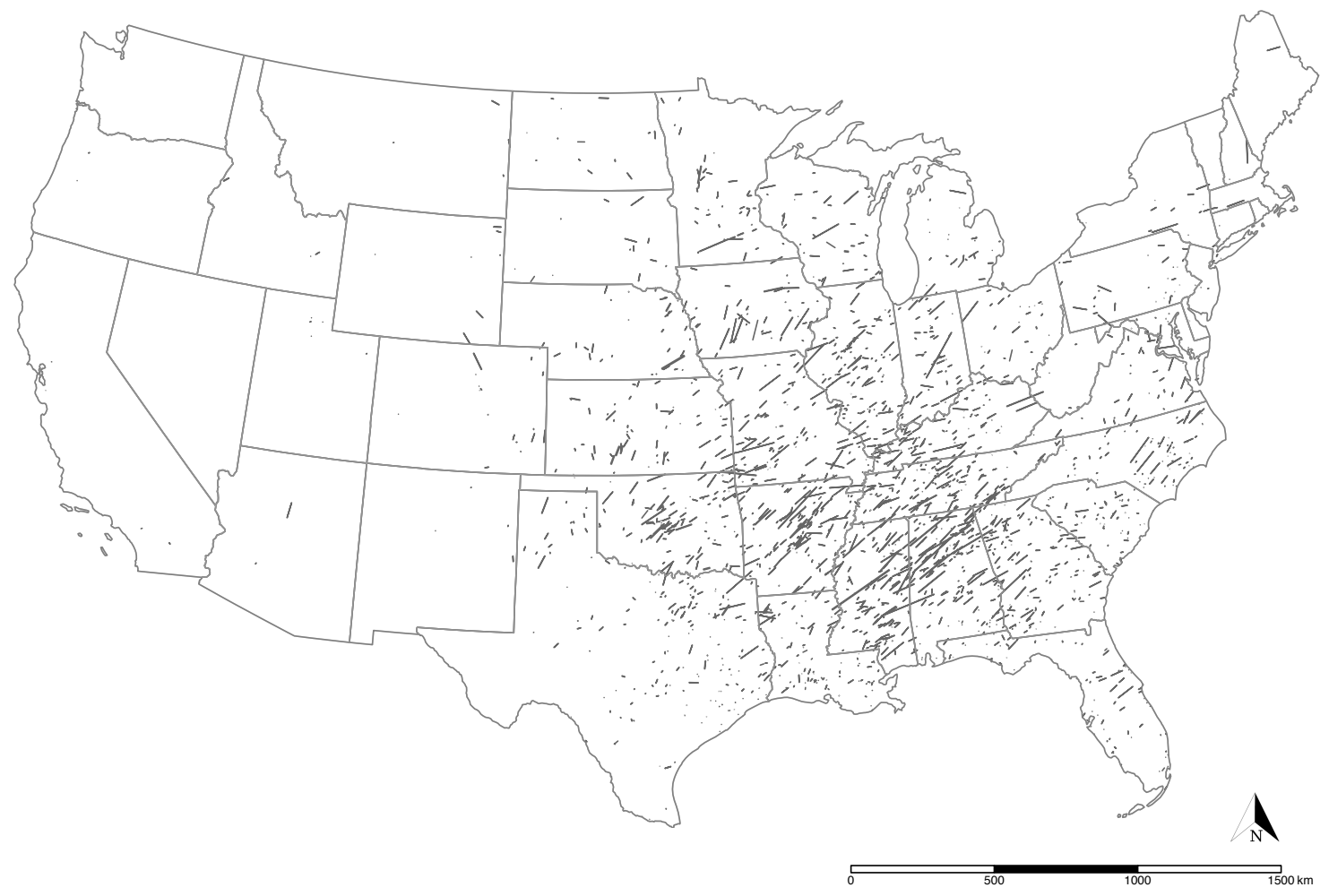


FIG. 2. Idealized models of tornado path and household median income. The straightline tornado track (arrow) and damage path (rectangle) are shown over household median income represented by the shaded square cells. The ratio of the fraction of the tornado path that falls within a Census tract (square cells) and the total area of the Census tract are determined by a percent overlay. The weighted estimates of each segment of the tornado path are added to determine an estimate of household median income for the entire tornado path.

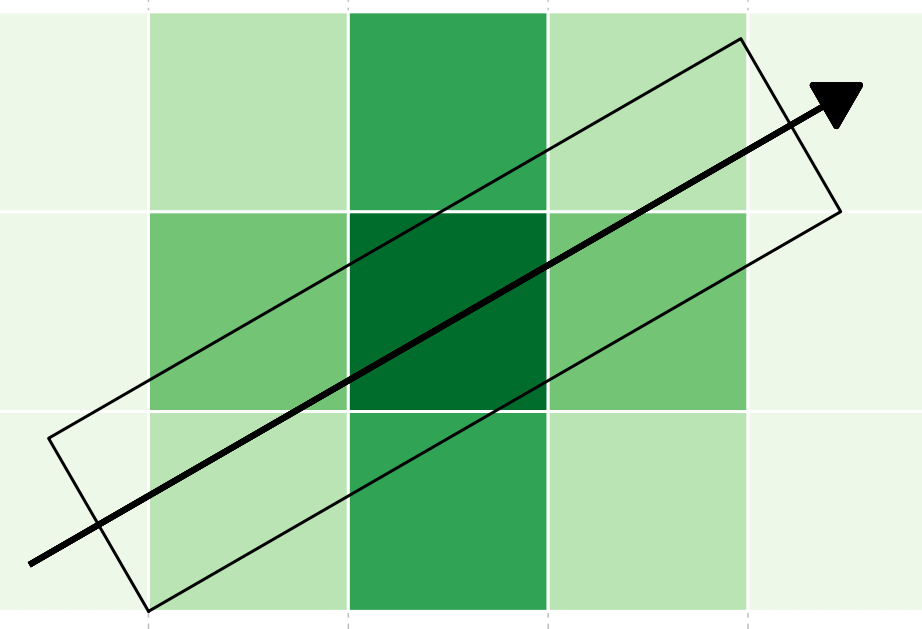

Household Median Income (USD)

$$
\begin{aligned}
& <\$ 10,000 \\
& \$ 10,000-\$ 20,000 \\
& \$ 20,001-\$ 30,000 \\
& \$ 30,001-\$ 40,000 \\
& >\$ 40,000
\end{aligned}
$$


FIG. 3. Actual and modeled paths for 20 casualty-producing tornadoes. The actual tornado paths are shown in red and the modeled tornado paths are shown in blue. Boundaries of the Census tracts are shown in gray.

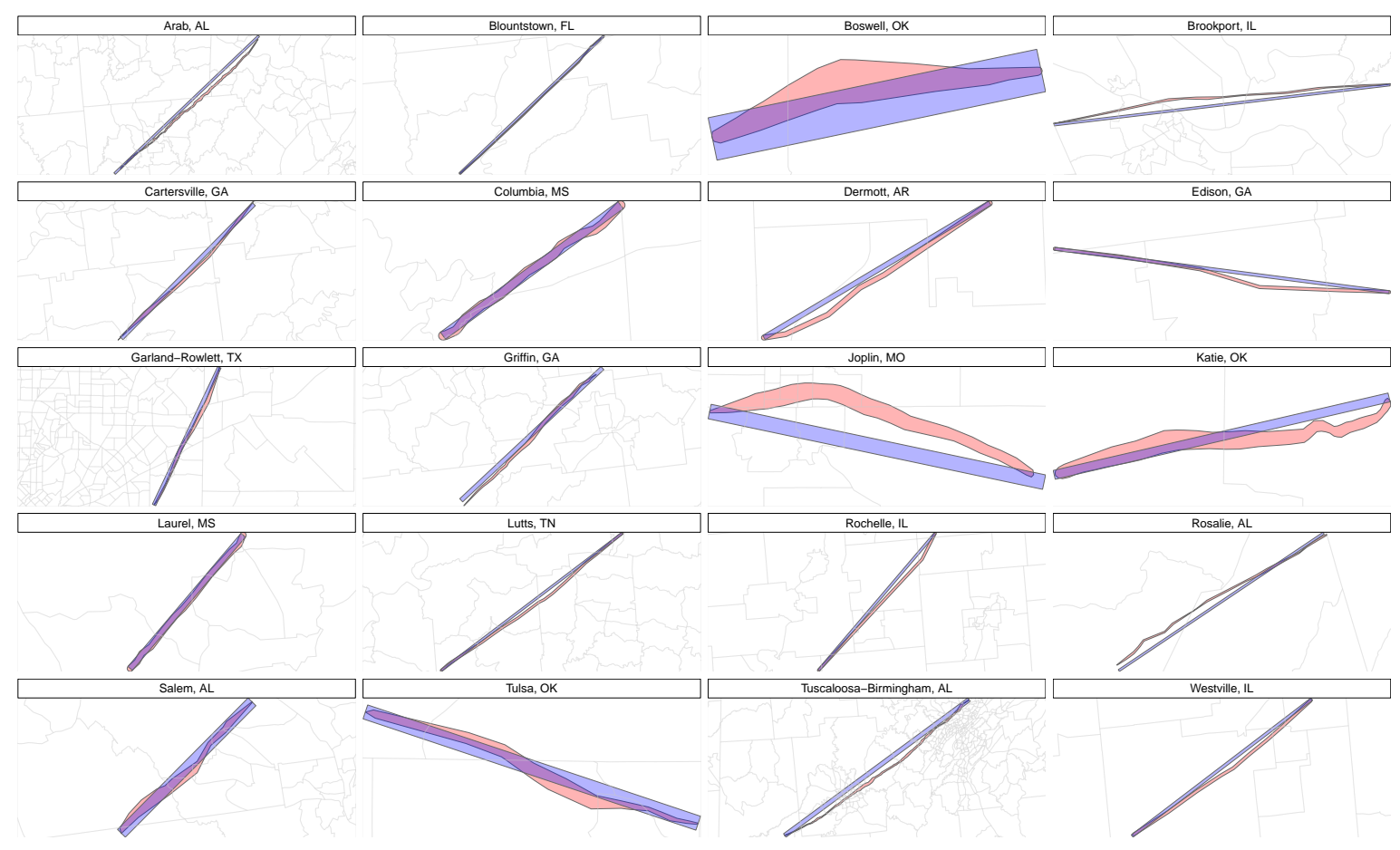


FIG. 4. (A) Observed and estimated number of male deaths and (B) observed and estimated number of female deaths.
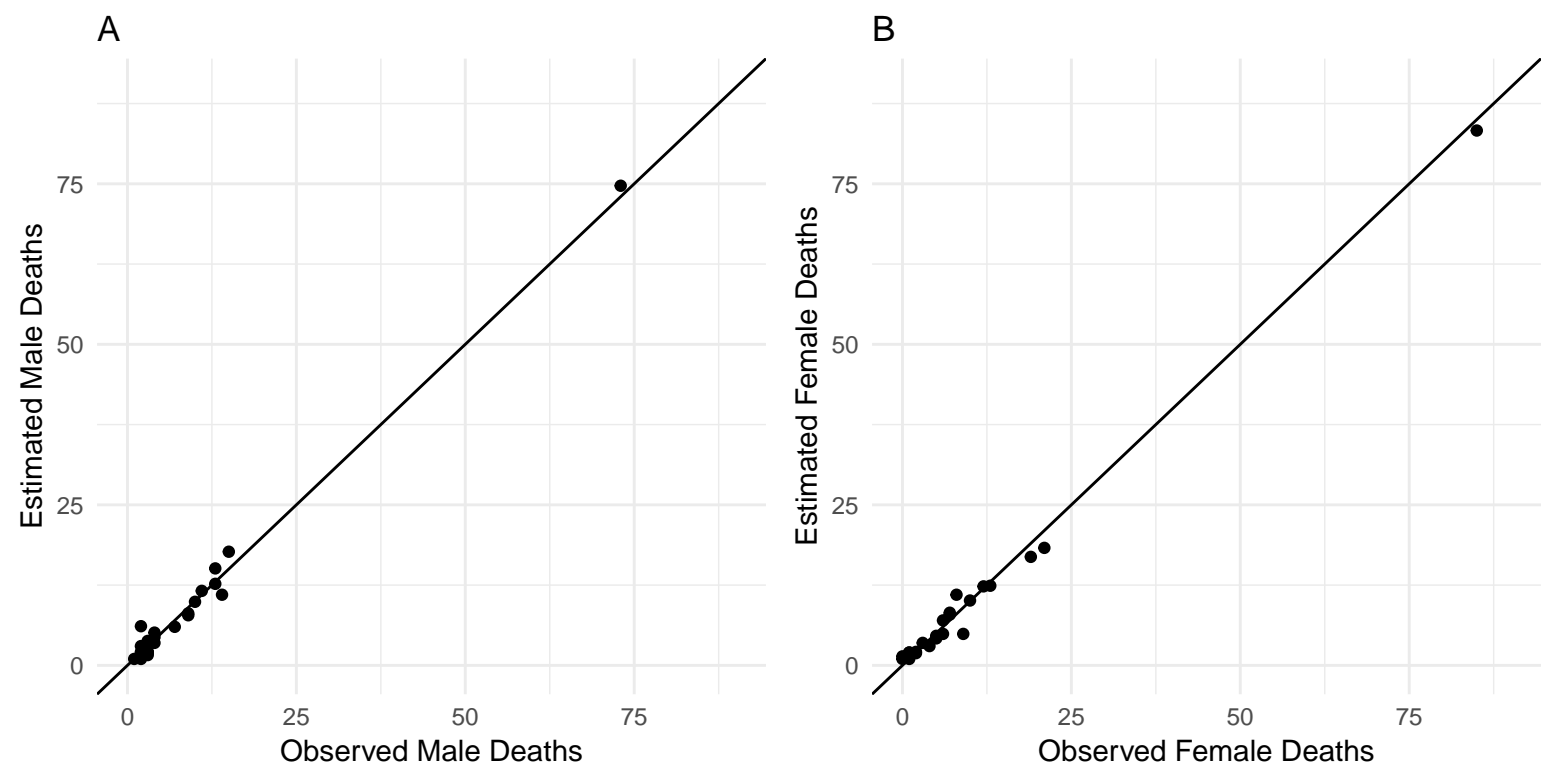
FIG. 5. (A) Observed and estimated number of deaths age under 18, (B) observed and estimated number of deaths age 18 to $44,(C)$ observed and estimated number of deaths age 45 to 64 , and (D) observed and estimated number of deaths age over 65 .

A

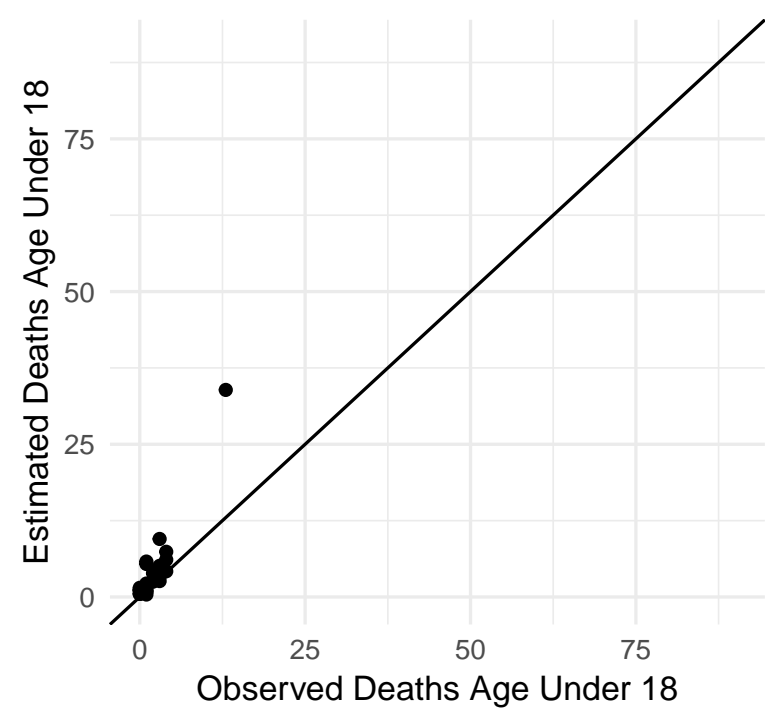

C

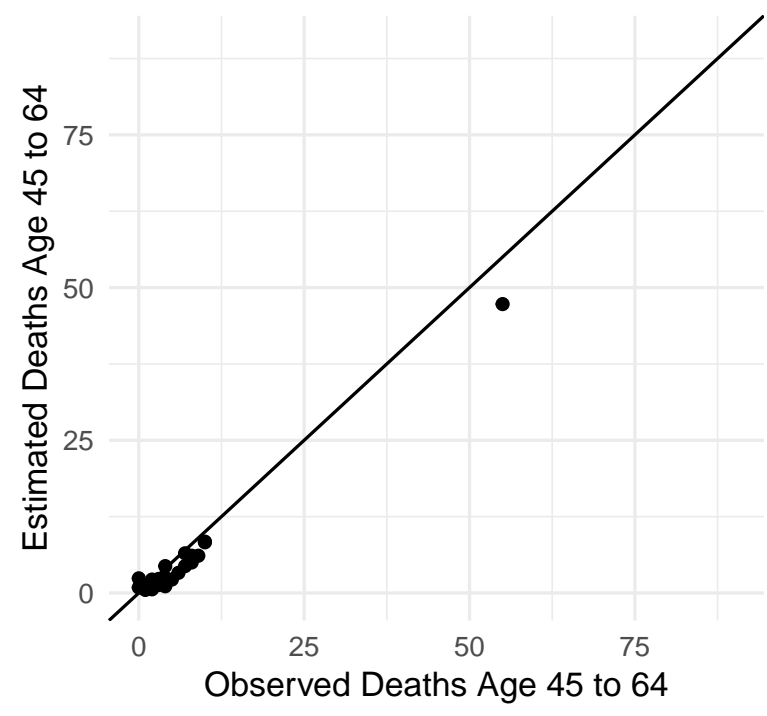

B

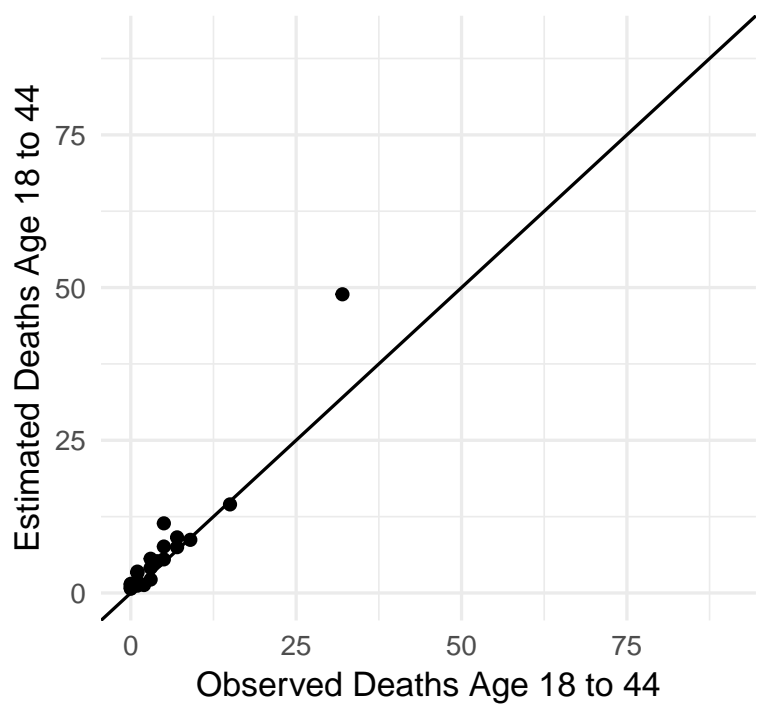

D

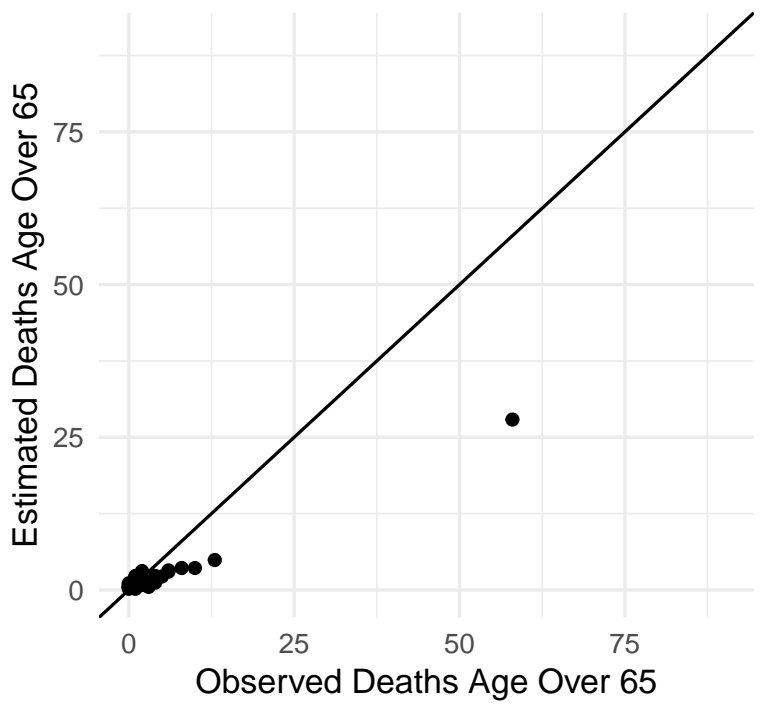


FIG. 6. Top ten tornadoes by (A) estimated white casualties and by (B) estimated black casualties.
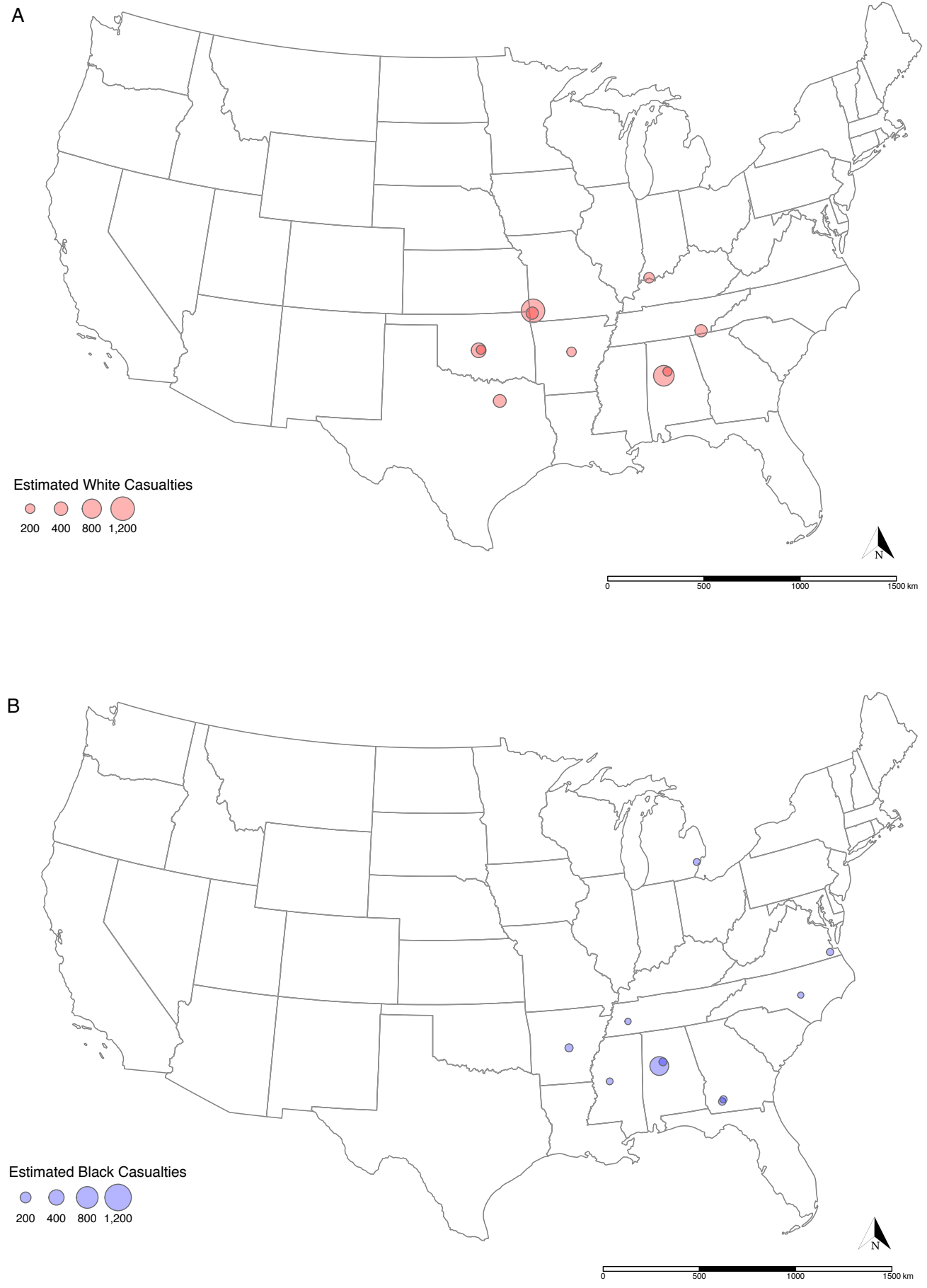
FIG. 7. Top ten tornadoes by (A) estimated young casualties and by (B) estimated elderly casualties.
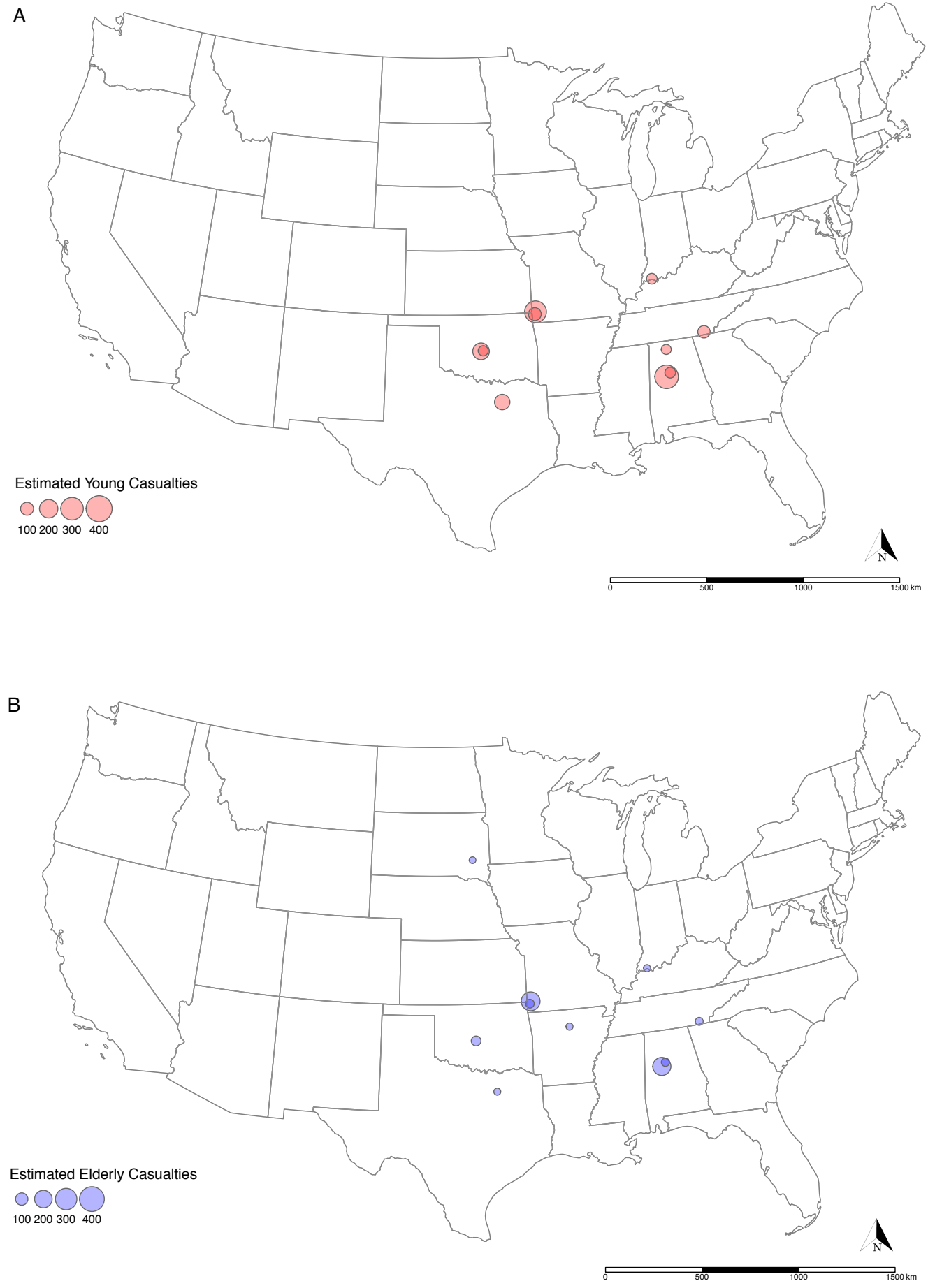